\title{
A Clinicomorphological Study of Scleroderma and Morphea
}

\author{
Karumbaiah K.P $\mathbf{P}^{1}$, Shivakumar $\mathbf{S}^{2}$ \\ ${ }^{1}$ Dr Karumbaiah K.P., Associate Professor, Department of Pathology, Kodagu Institute of Medical Sciences, Madikeri, \\ Karnataka, India, ${ }^{2}$ Dr S. Shivakumar, Professor and Head, Department of Pathology, Mandya Institute of Medical \\ Sciences, Mandya, Karnataka, India.
}

Author for Correspondence: Dr. K.P. Karumbaiah, Associate Professor, Departmrnt of Pathology, Kodagu Institute of Medical Sciences, Madikeri, Karnataka, India. E-mail: karumbaiahkp@yahoo.com

\begin{abstract}
Introduction: Cutaneous involvement is a prominent feature in connective tissue disease and the skin lesions are extremely important in diagnosing and subclassifying patients with these conditions. Scleroderma (Systemic sclerosis) and Morphea (Localized Scleroderma) are two common clinical conditions with skin involvement include in connective tissue diseases of skin. Scleroderma is usually a progressive and frequently fatal disease of unknown etiology. In Morphea (Localized scleroderma) the lesions usually are limited to the skin and to the subcutaneous tissue beneath the cutaneous lesions. Although their evolutions are divergent, they share similar histologic features. Objectives: 1 .To study various histological features in cutaneous lesions of systemic scleroderma and morphea. 2. To analyze overlapping features, possible transformation of one disease to the other and co-existence in this group of diseases. Methods: Clinically established / suspected cases of cutaneous lesions of systemic scleroderma and morphea were biopsied. After routine processing and paraffin embedding of formalin fixed tissue Haematoxyline and Eosin (H\&E) sections were studied along with special stain Verhoeff vangiesson (VVG). Results: Cutaneous lesions of 27 cases (9 cases of scleroderma and 18 cases of morphea) were studied and analyzed. Both the conditions were common in females. Conclusion: Though these two conditions vary in clinical manifestations, involvement of internal organs and types of autoimmunity, the cutaneous lesions share similar histologic features. Often it is necessary to use other diagnostic tools like serological and immunological study in conjunction with histopathology with the background of clinical history for a conclusive diagnosis.
\end{abstract}

Keywords: Scleroderma, Morphea, histopathologic features.

\section{Introduction}

The term connective tissue disease has evolved from older designation of "collagen disease" and "collagenvascular disease" and constitutes a group of multisystem diseases that are remarkably diverse and at the same time clinically similar in many aspects [1]. Scleroderma, one of the common conditions in this group of diseases, encompasses a spectrum of disorders, including Morphea, that strictly confined to the skin [2]. Dermal thickening and attachment of the skin to underlying tissues and Raynaud's phenomenon are usually the most apparent features of systemic sclerosis [3].Morphea is a chronic benign condition characterized by indurated areas of skin that are at first faint purple in

Manuscript received: $10^{\text {th }}$ March 2017

Reviewed: $20^{\text {th }}$ March 2017

Author Corrected: $27^{\text {th }}$ March 2017

Accepted for Publication: $2^{\text {nd }}$ April 2017 color but that eventually lose their color centrally leaving many ivory colored areas surrounded by a lilac ring [4].

Although the connective tissue diseases were originally grouped because they shared the pathologic feature of an acquired alteration in vascular and connective tissue structures, it has been the additional overlapping or sharing of many clinical and laboratory features that has maintained this classification. Diagnosing and subclassifying these cutaneous lesions are extremely important [1].

\section{Objectives}

1. To study various histological features in cutaneous lesions of systemic scleroderma and morphea. 
2. To analyze overlapping features, possible transformation of one disease to the other and coexistence in this group of diseases.

\section{Materials and Methods}

This was a prospective histopathologic study of cutaneous lesions of Scleroderma and Morphea undertaken by the department of pathology, J.S.S.Medical college, Mysuru, Karnataka. The study includes 27 cases of clinically diagnosed / suspected cases of scleroderma and morphea who attended the department of dermatology in a period of two years. A brief history was taken and dermatological examination was carried out to evaluate the type, distribution, configuration and topography of lesions. Clinically established / suspected cases were biopsied. After routine processing and paraffin embedding of formalin fixed tissue Haematoxyline and Eosin (H \& E) sections were studied along with special stain Verhoeff vangiesson (VVG).

Various histopathological changes were studied with clinical correlation. The diagnosis of Scleroderma and morphea was made based on the criteria described by Fleischmajor R et al (1972 [5].

Inclusion Criteria: The study includes all clinically diagnosed / suspected cases of scleroderma and morphea who attended the department of dermatology, and subsequently confirmed by histopathology during the study period.

Exclusion Criteria: Inadequate biopsies without subcutaneous tissue in clinically diagnosed / suspected cases of scleroderma and morphea were excluded in the study.

\section{Results}

Twenty seven clinically diagnosed / suspected cases were studied. Morphea (18cases) was more common compared to systemic sclerosis (9 cases) (Table 1). Both Scleroderma and Morphea are common in females (Table 2). While systemic scleroderma was more common between 41-50 years and localized lesion morphea was found more common in younger age group, between 21-30 years.

Table-1: Distribution of 27 cases of scleroderma and morphea.

\begin{tabular}{|c|c|}
\hline Disease & No. Of cases \\
\hline Scleroderma & 9 \\
\hline Morphea & 18 \\
\hline Total & 27 \\
\hline
\end{tabular}

Table-2: Sex distribution of 27 cases of scleroderma and morphea.

\begin{tabular}{|c|c|c|}
\hline Disease & No. Of cases & Male:Female Ratio \\
\hline Scleroderma & 9 & $1: 8$ \\
\hline Morphea & 18 & $1: 3.5$ \\
\hline Total & 27 & \\
\hline
\end{tabular}

Out of 18 cases of morphea diagnosed, 12 cases showed normal epidermis and other 6 cases showed epidermal atrophy. All 18 cases showed compact connective tissue in the dermis (Figure 1). Eccrine sweat glands showed reduced fat in all the cases. 2 cases showed hyalinised connective tissue in the subcutaneous tissue and 3 cases showed panniculitis (Figure 2). Table 3 shows the comparative histopathological changes observed in scleroderma and morphea.

Out of the 9 cases of scleroderma 5 cases showed normal epidermis and 4 cases showed epidermal atrophy. Compact connective tissue was seen in the dermis of all the cases.

Eccrine sweat glands Showed reduced fat in all the 9 cases. 1 case showed hyalinization of the connective tissue in the subcutaneous tissue. 
Research Article

Table-3: Comparative histopathological changes observed scleroderma and morphea.

\begin{tabular}{|c|c|c|}
\hline Histopathological Findings & Scleroderma & Morphea \\
\cline { 2 - 3 } & No. of cases [Total : 9] & No. of cases [Total : 18] \\
\hline Epidermis & 5 & 12 \\
\hline Normal & 4 & 6 \\
\hline Atrophic & & \\
\hline Dermis & - & - \\
\hline Connective tissue & 9 & 18 \\
\hline Normal & & 18 \\
\hline Compact & 9 & - \\
\hline Eccrine sweat glands & - & \\
\hline Fat reduced & & 2 \\
\hline Fat absent & & 16 \\
\hline Subcutaneous tissue & 1 & 18 \\
\hline Connective tissue & 9 & - \\
\hline Hyalinized & & 3 \\
\hline Compact & 1 & \\
\hline Fat & - & \\
\hline Reduced & & \\
\hline Absent & & \\
\hline Panniculitis & & \\
\hline & & \\
\hline
\end{tabular}

\section{Discussion}

Cutaneous involvement is a prominent feature in the connective tissue diseases and the skin lesions are extremely important in diagnosing and subclassifying patients with these conditions [1].

Scleroderma is a disease of the mesenchyme of unknown etiology and the symptoms and findings vary according to the location of the tissue involved, and may be limited or extensive [6]. Scleroderma and scleroderma-like conditions are classified broadly into Systemic sclerosis(SS), localized scleroderma(morphea), chemical induced scleroderma like conditions, eosinophilic fascitis, pseudoscleroderma and Graft-versus-host disease [1]. The present study of nine cases of systemic sclerosis(SS), findings underline female preponderance in these conditions (M:F ratio 1:8), as observed by Leinwand I et al (1954)[6], (M:F ratio 1:2.7) in a study of 150 cases and Fleischmajor R et al (1972)[5], (M:F ratio 1:2.3) who studied ten cases. There was a great variation in the age of onset, and majority of them were between 20 and 50 years of age.

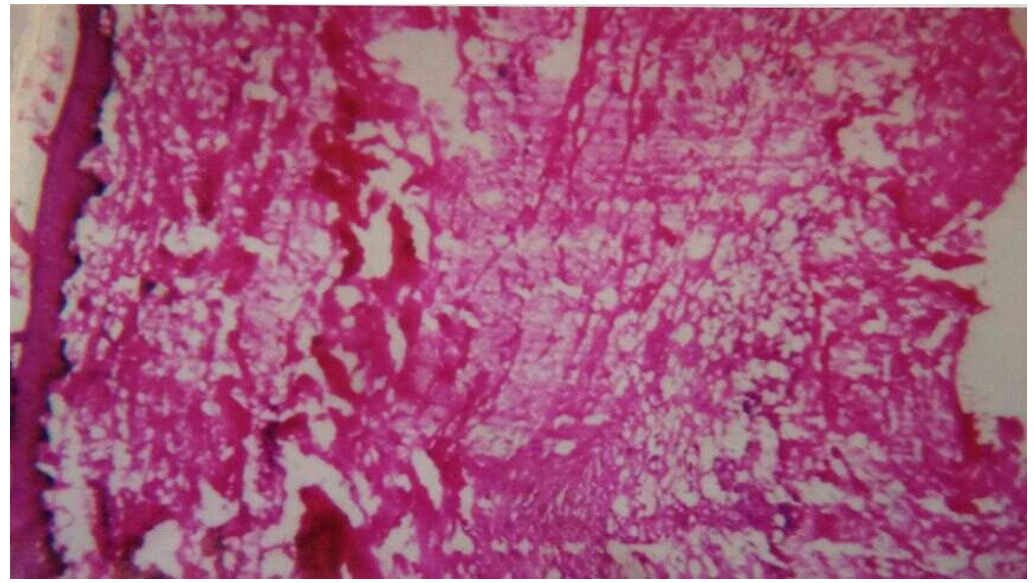

Figure-1: Morphea showing thinning of epidermis, compact dermal and subcutaneous collagen with panniculitis $(\mathrm{H} \& \mathrm{E}, 10 \times 10)$ 
Shono S et al (1991) [7] studied six cases of localized scleroderma (morphea) and all of them were women (M:F ratio $0: 6)$ between 7 and 34 years of age. In the present study of 18 cases of morphea, 14 were females and the other four cases were males (M:F ratio 1:3.5). Majority of them were between 21 to 30 years of age. Morphea was seen more commonly in the younger age group, compared to the systemic form of the disease.

Rarely, morphea and systemic scleroderma may coexist or the manifestations of systemic scleroderma precede those of morphea. Internal organs are often affected in scleroderma, but their involvement varies greatly in extent and degree [8]. The organs found to be frequently and significantly involved by this disease are the skin, gastrointestinal tract, lungs, kidneys, skeletal muscle and pericardium [3].

Systemic sclerosis with limited scleroderma, known as CREST syndrome, is associated with Raynaud's phenomenon in virtually all affected patients. The variant of acrosclerosis, which frequently but not invariably has a favourable prognosis, consists of several or all of the following manifestations: Calconosis cutis, Raynaud's phenomenon, involvement of Esophagus with dysphagia, Sclerodactyly and Telangiectases [8].

The pathogenesis of systemic scleroderma is uncertain and may be multifactorial. Histogenetic factors are essentially the same in morphea and systemic sclerosis; they differ only in degree and extent. The triad of vascular compromise, collagen matrix aberrations, and presence of serologic / autoimmune indicators contribute in variable degrees to symptoms and clinical findings in scleroderma and morphea [8].

A role of adhesion molecules in the evolution of lesions, eventuating in fibrosis has been suggested in scleroderma. Analysis of collagen in affected skin has shown excess production of connective tissue components normally present in the dermis, including types I,III,V, VI and VII collagen, fibronectin, and proteoglycans [8].

Most patients with systemic sclerosis (>90\%) and approximately 50\% with localized scleroderma (morphea) have a positive antinuclear antibodies (ANA) in the serologic/immunologic tests. The pattern may be homogenous, speckled, or nucleolar. When using human laryngeal carcinoma cell lines, Hep2, more than $90 \%$ of patients with morphea or acrosclerosis have a detectable anti-centromere antibody. In patients with systemic sclerosis this antibody is not usually detected. Instead, $20 \%$ to $40 \%$ of them have antibodies to Scl-70 (Anti-DNA-Tropoisomerase).

The presence of antibodies to Scl-70 correlate with systemic sclerosis, while the presence of anticentromere antibodies correlate with morphea or CREST and suggests a more favourable prognosis [8].

While indurated lesions are the common clinical presentation in systemic scleroderma, morphea may be divided according to morphology and distribution of lesions into six types: guttate, plaque, linear, segmental, subcutaneous and generalized [8].

In the present study all the 9 cases of scleroderma clinically presented with indurated lesions and most common type of lesion in morphea was of plaque type ( 8 cases), followed by indurated atrophic (4cases), and 3 cases each with hypopigmented macules and linear atrophic pigmented lesions.

In earlier studies done by Jaworsky C (1997) [9] and O'Leary PA et al (1957) [15], it was found that, the histopathologic changes in SS and morphea are similar. Though the changes were minimal in morphea, often it is not possible to differentiate these two types of scleroderma histologically.

In the present study compact connective tissue in the dermis and reduced fat around the eccrine sweat glands were seen in all the cases of SS and morphea.

Compact connective tissue in the subcutaneous tissue was seen in all the nine cases of SS and in 16 (out of 18) cases of morphea. Three cases of morphea showed panniculitis of subcutaneous fat (Figure 2). VVG stain done highlighted the collagen deposits in the dermis and subcutaneous tissue (Figure 3). 


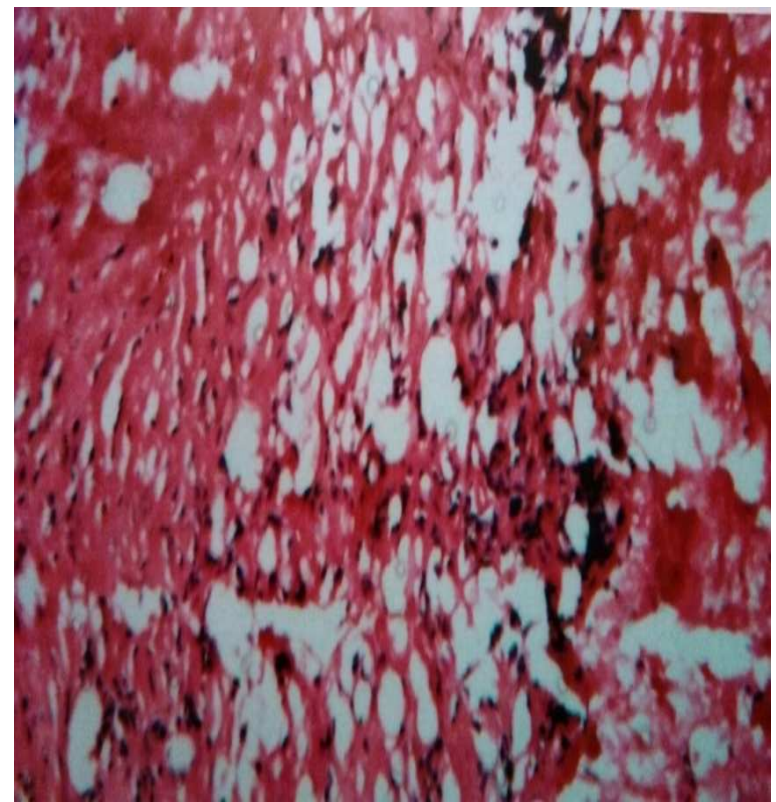

Figure-2: Morphea showing panniculitis (H\&E, 10x40)

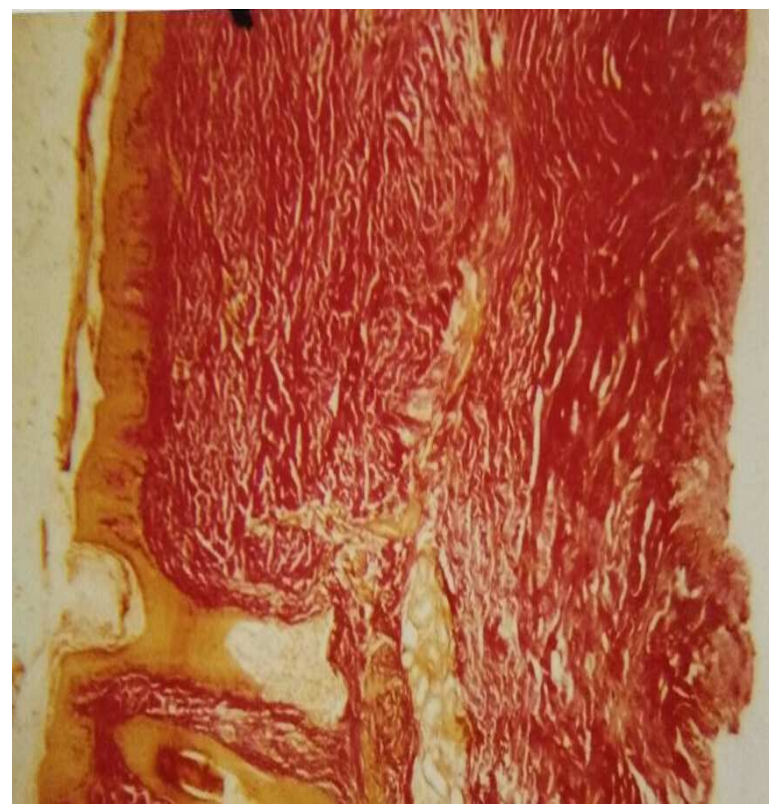

Figure-3: Scleroderma showing compact dermal collagen and replacement of subcutaneous tissue by collagen (VVG, 10x10)

Jaworsky C (1997)[9] pointed out that, mixed connective tissue disease and co-existing conditions associated with the presence of high titres of anti-UI RNP antibodies. In the present study a 29 year old male patient presented with a plaque type of lesion on the lower back and papular lesions on his right thigh which was clinincally diagnosed as morphea and lichen planus (an autoimmune disorder) respectively. The histopathologic study confirmed the diagnosis of co-existence of morphea and lichen planus in this case.

\section{Conclusion}

Cutaneous lesions of systemic scleroderma and localized or circumscribed scleroderma, morphea share common histopathological changes. Often it is impossible to differentiate these two lesions of uncertain pathogenesis based on histopathology alone. As connective tissue diseases of skin overlap both morphologically and in distribution often the diagnosis is difficult. Though the histological features are distinct and specific in some, often there is a overlapping of features and it requires a combination of histopathology, serological and immunological study with the background of clinical history for a conclusive diagnosis.

Funding: Nil, Conflict of interest: None initiated, Permission from IRB: Yes

\section{References}

1. Sontheimer RD, Euwer RL, Geppert TD, Cohen SB. Connective tissue diseases, Moschelle SL, Hurley HJ, Dermatology, Philadelphia: W.B Saunders Company; $2^{\text {nd }}$ edition, 1985.
2. Sappino AP, Masowye I, Saurat JH, Gabbian's G. Smooth muscle differentiation in Scleroderma fibroblastic cells. American Journal of Pathology 1990; 137: 585-591

3. D'Angelo WA, Fries JF, Masi AT, Shulman LE. Pathologic observations in systemic sclerosis (Scleroderma). A study of fifty-eight autopsy cases and fifty-eight matched controls. Am J Med. 1969 Mar: 46 (3):428-440.

4. Tremaine R, Adam JE, Orizaga M. Morphea coexisting with lichen sclerosus et atrophicus. Int $\mathbf{J}$ Dermatol. 1990 Sep;29(7):486-9.

5. Fleischmajer R, Damiano V, Nedwich A. Alteration of subcutaneous tissue in systemic scleroderma. Arch Dermatol. 1972 Jan;105(1):59-66.

6. Leinwand I,Duryee AW, Richter MN. Scleroderma; based on a study of over 150 cases. Ann Intern Med. 1954 Nov;41(5):1003-41. 
7. Shono S, Imura M, Ota M, Osaku A, Shinomiya S, Toda K. Lichen sclerosus et atrophicus, morphea, and coexistence of both diseases. Histological studies using lectins. Arch Dermatol. 1991 Sep;127(9):1352-6.

8. Lever WF. Histopathology of the skin. J.B. Lippincott, Philadelphia, 1949.
9. Jaworsky C. Connective tissue diseases in Histopathology of the skin. Philadelphia; Lippincott Raven, $8^{\text {th }}$ edition, 1997

10. O'Leary PA, Montgomery H, Ragsdale WE. Dermatohistopathology of various types of scleroderma. AMA Arch Derm. 1957 Jan;75(1):78-87.

\section{How to cite this article?}

Karumbaiah K.P, Shivakumar S. A Clinicomorphological Study of Scleroderma and Morphea. Trop J Path Micro 2017;3(2):90-95.doi: 10.17511/jopm.2017.i2.02. 